\title{
Apresentação
}

\section{Sociedade, direito, justiça. Relações conflituosas, relações harmoniosas?}

RAÚL ENRIQUE ROJO* E RODRIGO GHIRINGHELLI DE AZEVEDO**

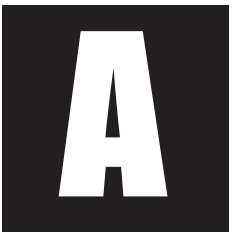

s origens da sociologia jurídica se confundem com as da sociologia. Com efeito, pode-se considerar, como o faz Jean Carbonnier (2004, p. 68-70), que L'Esprit des lois de Montesquieu, além de ser o primeiro trabalho importante de sociologia jurídica, é a primeira grande obra sociológica tout court. Montesquieu adotava nela uma visão empírica e relativista do Direito, o que Ihe granjeou, desde o momento do aparecimento do livro, as iras do Ancien Régime, a condenação da Sorbonne e sua inclusão no Índex Romano. Os ataques foram tão numerosos e tão violentos que Montesquieu se viu obrigado a publicar em 1750 (apenas dois anos depois de sua obra-prima), uma Défense de l'Esprit des lois. Adversários e defensores de L'Esprit des lois haviam compreendido perfeitamente bem, desde o começo, que Montesquieu introduzia um novo "esprit" na reflexão sobre o direito positivo e sobre suas relações com o direito natural. Este novo "espírito" consistia em procurar o conjunto de relações que as leis podem ter com as condições climáticas e geográficas, os tipos de vida,

\footnotetext{
* Professor do Departamento de Sociologia e dos Programas de Pós-graduação em Sociologia, em Direito e em Relações Internacionais da UFRGS. Endereço eletrônico: raulrojo@ufrgs.br

** Professor do Programa de Pós-graduação em Sociologia da UFRGS, com bolsa CAPES-PRODOC, na linha de pesquisa em Violência e Cidadania, e Coordenador do Curso de Especialização em Segurança Cidadã: Violência, Criminalidade e Polícia. Endereço eletrônico: rgdeazevedo@uol.com.br
} 
a religião, o comércio e os costumes, e em não só tratar de desvendar as relações que as leis podem ter entre si e com a intenção do legislador. L'Esprit des lois, para dizê-lo de outra forma, relacionava o Direito com todos os elementos do contexto político, social, econômico e cultural, assim como com o entorno físico e geográfico. O resultado era já uma sociologia jurídica, só que revestida com a linguagem do século XVIII.

No Prefácio da obra, Montesquieu resume aquela que hoje chamaríamos sua metodologia:

Examinei primeiro os homens, e achei que nesta infinita diversidade de leis e de costumes eles não eram conduzidos somente por suas fantasias. Coloquei os princípios como que por si mesmos, as histórias de todas as nações não serem mais do que suas conseqüências, e cada lei particular estar ligada a outra lei ou depender de outra mais geral... Não tirei meus princípios de meus preconceitos, e sim da natureza das coisas (Montesquieu, 1996, p. 5).

No século XVIII, evidentemente, uma declaração de fé desse tipo, empirista e positivista, bastava para sobressaltar muita gente. Hoje mesmo, relendo-a, voltamos a encontrar nela os fundamentos do método sociológico.

Alexis de Tocqueville era jurisconsulto, assim como Montesquieu (a quem, aliás, admirava sobremaneira). Não devemos esquecer que foi com o pretexto de fazer um estudo das instituições penitenciárias que ele empreendeu seu périplo através dos Estados Unidos em 1830, ainda que seu verdadeiro objetivo fosse, como é de pública notoriedade hoje, procurar a explicação (que finalmente seria profundamente sociológica) dos fundamentos e do funcionamento da democracia norte-americana. Até onde sabemos, apesar de tudo o que se tem escrito sobre essa obra, não se deu ainda o devido destaque à porção de sociologia jurídica que subjaz e que 
se encontra bem presente nela. Já que um dos fins explícitos que Tocqueville perseguia, como homem versado no Direito, era descobrir o peso relativo deste nas instituições democráticas norte-americanas. No início do capítulo IX onde faz o que ele mesmo chama de uma "espécie de resumo" de sua intenção e de seu pensamento, Tocqueville diz:

A república democrática subsiste nos Estados Unidos. O principal objetivo deste livro é fazer compreender as causas desse fenômeno... Julgara que todas as causas que tendem a manter a república democrática nos Estados Unidos poderiam reduzir-se a três: a situação particular e acidental na qual a Providência situou os americanos, constitui a primeira; a segunda decorre de suas leis; a terceira dos hábitos e costumes (Tocqueville, 1987, p. 213).

Este resumo corresponde bem ao plano da obra: todo o primeiro volume da Démocratie en Amérique é uma analise da importância relativa destes três fatores.

No que tange a Marx, parece evidente que, em boa parte de seus escritos sobre o Estado e sobre as relações de produção, poderíamos encontrar alguns dos elementos básicos de uma sociologia jurídica, que ele também colaborou para fundar. Faz mais de um quarto de século que Paul Phillips (1970), primeiro, e Maureen Cain e Alan Hunt (1979), depois, fizeram um levantamento dos principais textos em que Marx e Engels se referiram ao Direito, enquanto Jacques Michel (1983), Pierre Lascumes e Hartwig Zander (1984), de seu lado, traduziam e analisavam os primeiros artigos jurídicos de um jovem Marx ainda marcado por seus estudos de Direito.

Émile Durkheim, ao contrário, não teve uma formação jurídica. Sabese, porém, a importância que outorgava ao Direito na sua teoria da consciência coletiva e das solidariedades sociais (Durkheim, 1986). Em sua 
opinião, é segundo o tipo de direito que se pode distinguir empiricamente a solidariedade mecânica da solidariedade orgânica, pois a primeira está dominada pelo direito repressivo, assim como a segunda se caracteriza pelo direito restitutivo. O direito repressivo é a expressão de uma consciência coletiva forte, enquanto o direito restitutivo progride nas sociedades onde a consciência individual se desenvolve, ao passo que retrocede o império da consciência coletiva.

Para Durkheim, o Direito não só permite distinguir os dois tipos fundamentais de solidariedade social, mas também permite seguir a evolução das sociedades. A passagem do direito repressivo para o direito restitutivo é o índice da transição de um tipo de sociedade arcaica para um tipo de sociedade na qual a divisão do trabalho se faz mais elaborada e onde, por conseqüência, a solidariedade orgânica substitui a solidariedade mecânica.

É importante recordar também que em L'Année Sociologique, a publicação fundada por Durkheim e que ele dirigiu durante muitos anos, sempre se reservou um lugar especial à crítica das obras de Direito. Através dessa publicação, por seus trabalhos e seu ensino, Durkheim exerceu ademais uma profunda influência sobre um bom número de juristas (como Hauriou, Duguit, Renard, Lévy-Bruhl e Carbonnier) que intentaram interpretar o Direito desde uma perspectiva sociológica. Não é um exagero considerá-lo, conseqüentemente, como o pai indiscutível da sociologia jurídica francesa.

Dos fundadores da Sociologia, porém, quem mais prestou atenção ao Direito foi Max Weber (2001ª). ${ }^{1}$ A ele devemos os primeiros elementos de uma teoria da sociologia jurídica, cuja influência foi e continua sendo determinante. Poder-se-ia dizer, contudo, que, apesar de que a abordagem sociológica do Direito ocupou um lugar proeminente na teoria sociológica geral de Max Weber, seus comentadores a têm inexplicavelmente descuidado. É o que um deles (e não dos menores) tem reconhecido. 
Dizia, com efeito, Talcott Parsons: "Em minha opinião, não se tem apreciado devidamente que o âmago da teoria sociológica geral de Weber se encontra, em grande parte, na sua sociologia do direito" (Parsons, 1965, p. 174175). Seis anos depois, o mesmo Parsons voltava à carga: "Gostaria de deixar bem claro que o núcleo central da teoria sociológica geral de Weber não se encontra nem em suas abordagens dos problemas econômicos e políticos, nem em sua sociologia da religião, senão muito mais em sua sociologia do direito" (Parsons, 1971, p. 40). Não é este o lugar apropriado para desenvolver esta idéia de Parsons, basta sublinhar apenas que é a Weber a quem devemos as primeiras tentativas de uma tipologia sociológica do Direito, decisivos estudos sobre as relações entre direito e poder e, sobretudo, o descobrimento do papel desempenhado pelo Direito no desenvolvimento da racionalidade econômica e, em geral, do capitalismo no Ocidente. Foi também ele quem fez (numa obra quase desconhecida até há poucos anos) a primeira reflexão teórica sobre uma sociologia jurídica que não estaria dominada nem pelo estreito determinismo econômico de um certo marxismo, nem pelo idealismo jurídico que pretendia ser seu reverso (Weber, 2001b).

Haveria que mencionar ainda três nomes importantes da sociologia jurídica que, como Durkheim e Weber, se acham também associados às origens da Sociologia. Cronologicamente, o primeiro é o historiador inglês do Direito, Henry Sumner Maine, cuja obra principal, que data de 1861, dá início à história sociológica do direito dos países ocidentais (Maine, 1993). Sua teoria evolucionista da passagem da sociedade do estatuto à sociedade do contrato teria inspirado a Durkheim sua teoria da transformação das sociedades da solidariedade mecânica e do direito repressivo em sociedades caracterizadas pela solidariedade orgânica e pelo direito restitutivo.

\footnotetext{
2 Eugen Ehrlich nasceu em 1862 na cidade de Czernowitz (Bucovina do Norte), que formava parte então do Império AustroHúngaro e hoje, com o nome de Chernovtsy, integra a Ucrânia. Foi professor de direito romano e reitor da Universidade de sua cidade natal, cassado pelo anti-semitismo ali prevalecente depois que, em 1919, a província passou sob o controle da Romênia. De nada valeu seu brilhantismo nem sua conversão, ainda moço, ao catolicismo. Ehrlich morreu em Viena, amargurado e tuberculoso, em 1922, uns meses antes de cumprir os sessenta anos.
} 
O segundo dos "iniciadores" que gostaríamos de evocar aqui é o austríaco² Eugen Ehrlich, que, em 1913, publicou o primeiro tratado de "sociologia do direito" e que por isto é reconhecido por alguns como o "pai" da disciplina (Ehrlich, 1986). Quando menos, foi o primeiro a empregar esta denominação (hoje "désuète" e "vieillotte", como diz María José Fariñas Dulce, 1998) para designar a análise do "direito vivente", quer dizer do direito tal como ele é aplicado e utilizado, em oposição ao direito escrito ou teórico.

Deixamos para o final a figura mais secreta entre os "iniciadores", a menos conhecida hoje fora da Europa Central e Oriental. Referimo-nos a Leon Petrazycki, autor de uma vasta obra na qual se entrecruzam sociologia, psicologia, direito e moral (Petrazycki, 1955). Pouco se conheceria contudo dele, hoje, na Europa Ocidental e nas Américas, se não fosse pela devoção de alguns de seus discípulos como Jerzy Lande, Jan Górecki (1976) e, sobretudo, Adam Podgórecki (1980/1981), o autor da incomparável saga de Si-tien. ${ }^{3}$ Petrazycki, nascido em 1867 em Vitebsk, ${ }^{4}$ é com certeza o pai da sociologia polonesa e também da sociologia jurídica desta origem. Se sua influência, contudo, estendeu-se fora da Polônia foi mais, como dizíamos, por seus numerosos discípulos e por seus famosos alunos (da "diáspora russa") Pitirim Sorokin, Georges Gurvitch e Nicholas S. Timacheff, que pela real difusão de sua obra, escrita quase toda em alemão, russo ou polonês e pouco traduzida para línguas mais acessíveis. Contemporâneo de Weber e Durkheim, é possível, porém, como o aponta Podgórecki (1980/1981), que estes o tenham conhecido e estudado. O certo é que foi na Polônia, por causa provavelmente de Petrazycki, de seus

\footnotetext{
3 Conf. Podgórecki (1995), entre outros trinta e cinco volumes.

4 Esta cidade polonesa tinha sido incorporada à Rússia czarista menos de um século antes do nascimento de Petrazycki e continuou sendo um pólo cultural russo e germânico (pátria, entre outros, de Marc Chagall). Ocupada pelos alemães em 1941 (quando eliminaram à metade de sua população, de origem judaica), liberada e recuperada pela URSS, hoje forma parte da Belarus. Típico intelectual da Mittel Europa, Petrazycki (que dizia de si mesmo que "pensava em polonês, escrevia em alemão e lia em russo") fez seus estudos universitários em Kiev (Ucrânia) e Berlim (Alemanha), e lecionou nas Universidades de São Petersburgo (Rússia) e Varsóvia (Polônia), capital onde morreu em 1931.
} 
alunos e discípulos, que a sociologia jurídica alcançou, entre as duas guerras mundiais, o mais alto nível de produtividade teórica e empírica.

As linhas que precedem pretendiam recordar o lugar que ocupou o Direito no pensamento e nas teorias daqueles que Aron (1995) considerou os precursores (Montesquieu, Tocqueville e Marx) e os fundadores (Durkheim e Weber) da Sociologia. É, porém, um pouco paradoxal que esse interesse pela sociologia jurídica não tenha continuado depois. Os sociólogos pareceram perder o interesse pelo Direito, apesar de certas obras isoladas, em especial as de Gurvitch (2001), Henri Lévi-Bruhl (1962) e Timasheff (2001). Em realidade, foi como criminologia que a sociologia jurídica continuou sendo praticada, principalmente nos Estados Unidos, ainda que conservando apenas o direito penal como objeto de estudo. Com o rótulo "Law and Society", devem-se-Ihe numerosas pesquisas empíricas, especialmente sobre o funcionamento dos tribunais penais, que têm visto a luz sobretudo na Law and Society Review, publicada desde 1966 pela Law and Society Association, e, há pouco tempo, na sua quase homônima que, a partir de 2002, começou a ser publicada na Universidade de Califórnia em Santa Bárbara. Mas o vasto campo que abria para a sociologia jurídica o direito público, o direito privado e o direito internacional, continuou inexplorado durante muito tempo, quando menos pelos sociólogos, porque não devemos ignorar os trabalhos importantes de certos jurisperitos norte-americanos da primeira metade do século XX, em especial os de Roscoe Pound (1959) e Karl N. Llewellyn, que exerceram uma influência marcante entre os homens de formação jurídica. O último dos mencionados, aliás, associado a Edward Adamson Hoebel, está na origem da antropologia jurídica (Llewellyn e Hoebel, 2002).

Mas esses trabalhos não exerceram maior influência sobre a Sociologia nem deram lugar a uma sociologia jurídica ativa. Este fenômeno não é fruto do acaso. Pensamos que deve ser atribuído à posição quase hegemônica que gozou na academia, a partir dos anos 1960, a que Touraine 
(1987, p. 26) definiu como a "sociologia da suspeita e da caça ao ator". Esta, traduzindo em termos sociológicos a versão que Louis Althusser dava da obra de Karl Marx, desdenhou o estudo do Direito, considerado mero produto superestrutural das relações de produção e viu nas instituições espelhos deformados e deformantes dos sistemas de relações sociais, cuja realidade não podia (supostamente) reconhecer-se nelas.

Em verdade, foi apenas em meados dos anos 1980 que os sociólogos começaram a reconciliar-se com a tradição dos precursores e dos fundadores. Foi aparecendo um renovado interesse por uma sociologia jurídica que não teria unicamente por objeto o direito penal e que progressivamente se difundiu não só nos países germânicos ou anglo-saxões mas também nos de tradição latina, a um lado e outro do Atlântico, muitos dos quais estavam vivendo as seqüelas de processos de democratização pósditatorial conhecidos como a terceira onda (Huntington, 1994).

Hoje a sociologia jurídica está viva. No que se refere a suas orientações teóricas, o quadro se tem diversificado muito, ainda que se mencione com freqüência a constante importância de certos autores. Entre eles, os clássicos das ciências sociais: Marx, Durkheim e Weber, aos quais se acrescentam os clássicos da disciplina: Ehrlich, Theodor Geiger, Gurvitch ou, entre os mais recentes: Vilhelm Aubert, Carbonnier e Renato Treves. Alguns autores contemporâneos adquirem também uma importância comparável à dos clássicos, seja pelos trabalhos que inspiram ou pelas críticas que suscitam fora de seus países de origem. Trata-se amiúde de autores alemães, Luhmann e Habermas em primeiro lugar, assim como Foucault, Gunther Teubner ou ainda Donald J. Black. Um fenômeno particular é digno de menção: a importância, em muitos países, de autores que podem considerar-se como "autores nacionais emblemáticos". Entre estes, volvemos a encontrar os citados Petrazycki e Podgórecki na Polônia, Barna Horváth na Hungria, Boaventura de Sousa Santos em Portugal (e no mundo luso em geral), Per Stjernquist na Suécia ou Guy Rocher no Canadá. 
Independentemente dos autores considerados de maneira individual, existe um movimento teórico cuja vitalidade e influência são evidentes: os Critical Legal Studies. De origens imprecisas, esse movimento se consolidou por ocasião da conferência que teve lugar em 1977 na Universidade de Wisconsin, em Madison, reunindo numerosos professores que haviam ingressado nas universidades norte-americanas na década precedente e que reconheciam a influência dos autores da Escola de Frankfurt. Entre seus principais representantes podemos citar Duncan Kennedy, Mark Tushnet e Roberto Mangabeira Unger (1986). Também se podem identificar os efeitos de um movimento sistêmico-funcionalista cuja presença se manifesta, mais que por uma estrutura própria, por referências comuns e pelas fortes afinidades teóricas que podem observar-se entre diversos trabalhos realizados em distintos países. Finalmente, percebe-se (ainda que de maneira marginal) a importância que ganha, nos confins mesmos da sociologia jurídica, a tendência "Law and Economics" (Kiriat, 1999).

No que tange aos domínios de pesquisa, o melhor estudado, objeto de trabalhos em todo lugar onde a sociologia jurídica conhece um certo desenvolvimento empírico, é o das instituições que asseguram a produção (e a reprodução) do Direito: os tribunais, as profissões jurídicas, a polícia, etc. Vêm em segundo lugar as pesquisas que se referem à efetividade e aos efeitos do direito: estes concernem às vezes a domínios particulares (a família, a empresa, a proteção do meio ambiente, etc.), focalizam-se nos fenômenos de ineficácia (marginalidade e divergência), ou avaliam ainda a eficácia dos instrumentos jurídicos na prevenção ou resolução dos conflitos ou das demandas renovadas (políticas e sociais) de uma instância simbólica que deve agir seguindo formas adjudicatórias e que teria que dizer o que é justo. Vêm depois outras duas categorias: por um lado, o estudo dos fenômenos de pluralismo normativo e, por outro, o dos fenômenos de produção do direito, dos processos legislativos e de seu contexto social. 
Quanto à sua institucionalização, a sociologia jurídica revela, antes de mais nada, uma grande diversidade. Não só a disciplina se acha mais ou menos bem implantada, de acordo com o país de que se trate, como sua implantação segue, em cada país, modalidades muito diferentes, dando, por exemplo, preferência, em alguns deles, às instituições de pesquisa e, em outros, ao ensino universitário. Em face da importância das instituições estatais, observa-se uma importância variável das instituições privadas, em particular das associações, das revistas ou ainda das coleções de trabalhos especializados. A este respeito não podemos deixar de mencionar os que poderíamos denominar "momentos fortes" de nossa disciplina, oferecidos pelos congressos e outros encontros científicos periódicos.

No universo da própria sociologia jurídica, a evolução mais sensível que, a nosso juízo, produziu-se nesses últimos tempos, é a importância crescente dos marcos não nacionais, quer dizer, das redes regionais e internacionais. Podemos, assim, reconhecer diversas regiões caracterizadas por afinidades teóricas e até por relações mais ou menos institucionalizadas de cooperação. Entre elas, a Europa latina, estruturada em torno do "Cercle de Sociologie et de Nomologie Juridiques" que anima André-Jean Arnaud; a Europa germânica, onde se afirma o dinamismo das redes alemãs, seguido atentamente por Itália e os países da Europa Central e Oriental; a Escandinávia, dona de uma antiga tradição de cooperação, que também parece influenciada pelos trabalhos levados adiante na região germânica; os países anglo-saxões nos quais a Law and Society Association tem criado fortes vínculos; e a América Latina, por fim, onde se celebram, desde 1987, reuniões de jurisociólogos latino-americanos e onde é remarcável uma série de iniciativas adotadas pelo Instituto Latinoamericano de Servicios Sociales, entre elas a revista Más allá del derecho, lançada faz já quinze anos.

Este tecido regional e mundial se tem reforçado sensivelmente no decurso dos últimos anos, sendo a criação do Instituto Internacional de Sociologia Jurídica em Oñati (País Basco espanhol) um dos passos decisi- 
vos em tal sentido. Esta instituição, única em seu gênero, foi fundada em 1988 pelo Governo Autonômico Basco e pela Comissão de Pesquisa Sociojurídica (RCSL) da Associação Internacional de Sociologia (ISA). Suas incumbências principais têm sido a criação de um centro de documentação sobre a sociologia jurídica (que possui uma riquíssima biblioteca sobre a disciplina e conta com uma base de dados com mais de 42.000 referências bibliográficas), a promoção de reuniões e encontros de especialistas na matéria, a organização de retiros para que os pesquisadores possam desenvolver suas teorias no magnífico quadro da Antiga Universidade de Oñati, bem como a criação de um mestrado anual e de cursos de verão. Outro signo de vitalidade da sociologia jurídica é o número crescente de revistas especializadas que lhe são consagradas. Mencionemos, entre elas: Aissymnitis (Grécia); Anuário Vasco de Sociología del Derecho (País Basco espanhol); Anuário de Sociología y Psicología Jurídica (Catalunha, Espanha); Australian Journal of Law and Society; Canadian Law and Society Journal — Revue Canadienne de Droit et Société; Crítica Jurídica (México); Droit et Société, (França); Hoshakaigaku — The Sociology of Law (Japão); International Journal of the Sociology of Law (Reino Unido); Jahrbuch für Rechtssoziologie und Rechtstheorie (Alemanha); Journal of Law and Society (Reino Unido); Law \& Society Review (EUA); Law in Context (Austrália); Recht en Kritiek (Holanda); Revista de Sociología del Derecho (Argentina); Revue interdisciplinaire d'Etudes juridiques (Bélgica); Sociologia del Diritto (Itália); Tidskrift för rättsociologi (Suécia); Zeitschrift für Rechtssoziologie (Alemanha).

O presente número de Sociologias testemunha precisamente a vitalidade da sociologia jurídica. Em primeiro lugar, pelo caráter internacional dos colegas que aceitaram generosamente colaborar em nosso dossiê, pois ele reúne trabalhos provenientes de Portugal, Suíça, Espanha e Brasil. E a testemunha também pela diversidade dos temas abordados. Todavia, no meio desta riqueza temática, é possível isolar certas idéias fortes como a regulação social pelo Direito, à qual tem sido consagrado este dossiê. Mais especifica- 
mente, as contribuições são focalizadas sobre dois conjuntos de questões: por uma parte, a especificidade das normas jurídicas, as distinções que é preciso realizar entre elas e as relações que mantêm entre si e com os órgãos encarregados de sua aplicação; por outro lado, a relação do Direito com o poder, que pode ser percebida tanto no nível do controle social como no da elaboração da regra jurídica, de sua administração ou de sua aplicação nos casos litigiosos, o que levanta, neste último caso, a questão dos juízes e tribunais que procedem a esta operação.

Abre este dossiê um texto teórico. Nele Raúl Enrique Rojo intenta elucidar as relações, freqüentemente implícitas, entre Direito, poder e dominação. Questão que é preciso colocar se consideramos o jurídico não como um campo específico que pode ser isolado de outros modos de regulação social, mas como uma das formas de existência das relações sociais numa sociedade dada e, mais especificamente, como um modo de legitimação do poder. Para Rojo a sociologia jurídica só pode ser concebida como uma parte de uma disciplina mais vasta: uma sociologia do poder e da dominação. Para isso, nosso autor retoma o fio do debate sobre o poder que se levou adiante durante as últimas décadas e classifica as definições que deste têm sido propostas durante o debate, agrupando-as em voluntaristas, sistêmicas e críticas. Aborda em seguida a contribuição de Max Weber a esse debate, acabando por deter-se no papel do Direito nos conflitos, nas relações de poder e dominação e nas dimensões simbólicas do Direito. Finalmente, aborda o vínculo que quase todas as teorias reconhecem entre o monopólio estatal da violência legítima e o direito, pondo de ressalto quanto de pretensão tem esta reivindicação do Estado, e o papel do jurisociólogo na polis.

Boaventura de Sousa Santos discute como, a partir da década de 1990, a problemática da relação entre os tribunais e as novas tecnologias de comunicação e de informação (NTCl) e, em especial, da relação entre os tribunais e a comunicação social, coloca novas questões para uma aná- 
lise das relações entre as instituições de justiça e a sociedade. De um lado, coloca-se a questão da vontade e da capacidade do Estado e do Direito para regular as novas tecnologias e os novos interesses de comunicação e de informação, bem como para incriminar e punir as novas atividades socialmente danosas que, por via delas, tornaram-se possíveis. De outro lado, o impacto da expansão exponencial das novas tecnologias e dos novos interesses informacionais e comunicacionais no Direito e nas suas instituições, nomeadamente os tribunais. Analisando esta segunda vertente, o artigo de Sousa Santos discute questões como a informatização dos tribunais, as novas técnicas de gestão e seu impacto nas relações inter-profissionais, o impacto da mediatização da justiça na funcionalidade interna dos tribunais e nas regras e estilos de atuação profissional, assim como o impacto das novas tecnologias de comunicação e de informação e, sobretudo, dos meios de comunicação na relação entre os tribunais e a sociedade informatizada e mediatizada. Conclui afirmando a necessidade de explorar as potencialidades democráticas das novas tecnologias, as novas possibilidades de democracia deliberativa e participativa, as novas formas de controle público, tanto do Estado como da produção privada de bens públicos.

O texto de Maria da Gloria Bonelli ilustra bem a tentativa de problematizar o processo de construção da identidade dos magistrados enquanto categoria profissional, contrastando o ideário dominante no Tribunal de Justiça do Estado de São Paulo (TJESP), com o ideário difundido pela Associação dos Juízes para a Democracia. As disputas em torno do conteúdo do profissionalismo são tomadas como indicativas da luta cognitiva entre identidades coletivas distintas na magistratura. $\mathrm{O}$ trabalho desenvolve reflexões sobre formas identitárias, ideologia do profissionalismo e mídia, procurando articulá-las na compreensão do fenômeno profissional na atualidade. A pesquisa apóia-se na idéia de que as formas identitárias são modos de identificação dos indivíduos e concebe o profissionalismo como um campo com contornos mutáveis devido às diferentes visões so- 
bre isenção e compromisso político, sobre ética e responsabilidade profissional. A visibilidade pública da magistratura constitui-se no principal material de análise, tanto no periódico oficial do TJESP e naquele em que os juízes apresentam uma alternativa à atuação desta instituição quanto na grande imprensa paulista. As identificações profissionais dos juízes são vistas como resultado não só das interações práticas, mas da forma como eles se vêem e são vistos nos meios técnicos de difusão de bens simbólicos.

A análise que Jacqueline Sinhoretto leva adiante propõe-se a interpretar situações observadas em pesquisa de campo realizada em um equipamento público inovador quanto à organização dos serviços de justiça e segurança: os Centros de Integração da Cidadania - $\mathrm{CIC}$, programa governamental desenvolvido em São Paulo, que visa melhorar o acesso à justiça e à cidadania e ainda a segurança das populações residentes em bairros periféricos. O programa apóia-se na visão de que a democratização da sociedade brasileira relaciona-se intimamente com a adoção, pelos órgãos da Justiça, de outras funções e feições: ao invés de agentes da repressão penal na periferia, os operadores da justiça, a partir dos $\mathrm{CIC}$, passariam ao papel de agentes da efetivação da cidadania nos espaços de maior exclusão social. Com um referencial analítico foucaultiano em que é central o tema da corporificação - a produção cultural e política dos corpos -, a autora busca saber em que medida o desempenho dos operadores no programa indica possibilidades políticas de resistência, introduz rupturas na constante diferenciação entre os corpos, que caracteriza a atividade judicial clássica, abre possibilidades para a emergência de uma nova corporificação dos agentes públicos da justiça, reduzindo a desigualdade entre operadores e cidadãos comuns. Ao longo do texto, são desvendados os sutis mecanismos pelos quais a atuação do Estado cria efeitos de validação do poder de uma classe sobre as outras.

Jean-François Perrin discute as conseqüências do aumento da complexidade dos sistemas normativos contemporâneos, especialmente no que 
diz respeito à teoria contratualista baseada na idéia do consentimento livre e totalmente informado por parte dos indivíduos contratantes. Segundo o autor, a ficção liberal que coloca a gênese do jurídico na vontade do sujeito precisa ser repensada, ante a densidade extraordinária da produção normativa e da complexidade sem precedentes nas relações que se estabelecem entre diferentes sistemas de normas, fenômeno caracterizado como de internormatividade. No campo normativo, este fenômeno de expansão e complexificação da juridificação se traduz na emergência de novos domínios de especialização, imbricando uma série de conhecimentos díspares, concorrentes ou complementares, com o nascimento de novas profissões e o surgimento de modos alternativos de resolução de conflitos. Imerso em um meio normativo superabundante e cheio de antinomias, o indivíduo social perde sua autonomia e, na maioria dos casos, converte-se em um autômato, submetendo sua vontade aos propósitos normativos impostos pelos vários subsistemas. Utilizando-se dos conceitos de pluralismo débil e pluralismo forte para contrastar as diferentes interpretações do fenômeno, o autor conclui indagando como pode o indivíduo social defender sua personalidade neste mundo hipercomplexo e carregado de contradições normativas propondo como alternativas a circulação de informações e a mobilização dos recursos clássicos do Direito para a proteção da pessoa humana.

Com sua severidade crítica proverbial, Roberto Bergalli aborda uma questão bem atual: as relações entre os mecanismos de controle punitivo e a globalização. $\mathrm{O}$ autor parte da exposição analítica das diferenças entre as categorias controle social e controle punitivo. A partir desta distinção, Bergalli trata da incidência das transformações mais recentes nas noções de tempo e espaço no terreno das disciplinas físico-matemáticas e destaca a inadequação dos conceitos e instituições ligados às disciplinas sociais e jurídicas para lidar com esta nova situação. A partir destes elementos, a exposição parte para a análise da globalização e dos distintos fenômenos 
que ela produz, especialmente no que diz respeito às transformações que se constatam no que atualmente se pode entender como controle social, e conclui afirmando que, ante a morte do welfare, do fordismo e do Estadonação, a sociedade disciplinar dá lugar à sociedade do controle punitivo pelo medo.

Fecha esse dossiê Rodrigo Ghiringhelli de Azevedo, abordando a questão da justiça penal na América Latina. Partindo de uma apresentação dos indicadores que permitem avaliar o grau de democratização do sistema de justiça penal, o autor constata a enorme defasagem neste âmbito para a consolidação do processo de transição democrática no Continente. Analisando especificamente a situação no Brasil e na Argentina, são apontadas as deficiências no funcionamento das instituições responsáveis pelo controle do crime, assim como o aumento das taxas de criminalidade, como fatores que resultam em uma crescente perda de legitimidade do sistema, incapaz de justificar o seu alto grau de seletividade e de arbítrio. Ao final, são apresentadas algumas alternativas para o aperfeiçoamento institucional, entre as quais, a atuação dos cientistas sociais com a produção de pesquisas e análises se coloca como um elemento central para a elaboração de novas alternativas para lidar com a conflitualidade social contemporânea.

Os juristas e os sociólogos que, via de regra, não têm oportunidade de participar de debates de idéias como os sugeridos por estes trabalhos, encontraram neles um certo número de questões sobre as quais basear sua reflexão comum. O diálogo entre Direito e Ciências Sociais é muitas vezes problemático. Sentimos esta pluralidade de leitura através de preciosas discordâncias que resplandecem nos trabalhos aqui reunidos e que são outros tantos pontos reveladores da honestidade intelectual de seus autores. Preciosas discordâncias: elas nos oferecem, longe de toda pretensão dogmática, as luzes que nos permitem entrever a possível harmonia do verdadeiro diálogo interdisciplinar. Desde este ponto de vista, pensamos que o objetivo perseguido pelo dossiê foi alcançado. E esta deveria 
Sociologias, Porto Alegre, ano 7, no 13, jan/jun 2005, p. 16-34

ser a medida para julgar seu eventual sucesso.

\section{Referências}

ARON, Raymond. As etapas do pensamento sociológico. São Paulo: Martins Fontes, 1995.

CAIN, Maureen e HUNT, Alan. Marx and Engels on law. Londres, Nova lorque e San Francisco: Academic Press, 1979.

CARBONNIER, Jean. Sociologie juridique. Paris: PUF, 2004.

DURKHEIM, Emile. De la division du travail social. Paris: PUF, 11ª. ed., 1986.

EHRLICH, Eugen. Fundamentos da sociologia do direito. Brasília: Editorial da Universidade de Brasília, 1986.

FARIÑAS DULCE, María José. Prolégomènes. In: ARNAUD, A. J. e FARIÑAS DUL$\mathrm{CE}, \mathrm{M}$. J. Introduction à l'analyse sociologique des systèmes juridiques. Bruxelas: Bruylant, 1998.

GÓRECKI, Jan. Sociology and jurisprudence of Leon Petrazycki. Urbana [IL]: University of Illinois Press, 1976.

GURVITCH, Georges. Elementos de sociología jurídica. Granada: Comares, 2001.

HUNTINGTON, Samuel P. La tercera ola. La democratización a finales del siglo XX. Barcelona, Buenos Aires e México: Ediciones Paidós, 1994.

KIRIAT, Tierry. Economie du droit. Paris, La Découverte, 1999.

LASCOUMES, Pierre e ZANDER, Hartwig. Marx: du vol de bois à la critique du droit. Karl Marx à la Gazette rhénane, naissance d'une méthode. Paris: PUF, 1984.

LÉVY-BRUHL, Henri. Sociología del derecho. Buenos Aires: EUDEBA, 1962.

LLEWELLYN, Karl N. e HOEBEL, E. Adamson. The Cheyene way: conflict and case law in primitive jurisprudence. Buffalo [N.Y]: W.S. Hein \& Co., 2002. 
MAINE, Henry Sumner. El derecho antiguo: considerado en sus relaciones con la historia de la sociedad primitiva y con las instituciones modernas. Madri: Civitas, 1993.

MICHEL, Jacques. Marx et la société juridique. Paris: Publisud, 1983.

MONTESQUIEU, Charles de Secondat, barão de La Brède e de. O espírito das leis. São Paulo: Martins Fontes, 1996.

PARSONS, Talcott. Max Weber, 1864-1964. American Sociological Review, Albany [NY], vol.30, no 2, 1965, p. 174 e sigtes.

PARSONS, Talcott. Value-freedom and objectivity. In: STAMMER, O. (organizador). Max Weber and sociology today. Oxford: Basil Blackwell, 1971.

PETRAZYCKI, Leon. Law and morality. Cambridge [MA]: Harvard University Press, 1955. PHILLIPS, Paul. Marx and Engels on law and laws. Totowa [NJ]: Barnes \& Noble, 1970. PODGÓRECKI, Adam. Unrecognized father of sociology of law. Reflections based on Jan Górecki's Sociology and jurisprudence of Leon Petrazycki, Law and Society Review, Beverly Hills, vol. 15, n. 1, 1980-1981, p. 183-202.

PODGÓRECKI, Adam. One hundred and one stories of Si-tien. Ottawa: Carleton University, 1995.

POUND, Roscoe. Examen de los intereses sociales. Tradução de Alberto Ciria. Buenos Aires: Editorial Perrot, 1959.

TIMASHEFF, Nicholas S. An introduction to the sociology of law. New Brunswick [NJ]: Transaction Publishers, 2001.

TOCQUEVILLE, Alexis de. A democracia em América. Belo Horizonte e São Paulo: Editora Itatiaia e EdUSP, 3a. ed., 1987.

TOURAINE, Alain. Les écoles sociologiques. In: PAQUOT, T. (organizador) La sociologie en France. Paris: La Découverte, 1987, p. 26-41.

UNGER, Roberto Mangabeira. The Critical Legal Studies Mouvement Cambridge Recebido: 25/11/2004 
Sociologias, Porto Alegre, ano 7, no 13, jan/jun 2005, p. 16-34

\section{Resumo}

As origens da sociologia jurídica se confundem com as da sociologia. Assim resulta do interesse que dispensaram ao Direito e aos temas jurídicos tanto os que Raymond Aron considerou os precursores (Montesquieu, Tocqueville e Marx) como os fundadores (Durkheim e Weber) da sociologia. É, porém, um pouco paradoxal que este interesse pela sociologia jurídica não tenha continuado depois. Os sociólogos pareceram desinteressar-se pelo Direito, apesar de certas obras isoladas, em especial as de Gurvitch, Lévi-Bruhl e Timasheff. Em realidade, foi como criminologia que a sociologia jurídica continuou sendo praticada, principalmente nos Estados Unidos, ainda que conservando apenas o direito penal como objeto de estudo. Este fenômeno não é fruto do acaso, deve ser atribuído à posição quase hegemônica que gozou na academia, a partir dos anos 1960, uma sociologia da suspeita e da caça ao ator, que desdenhou o estudo do Direito, considerado mero produto superestrutural das relações de produção, e viu nas instituições espelhos deformados e deformantes dos sistemas de relações sociais. Em verdade, recém a meados dos anos 1980 os sociólogos começaram a reconciliar-se com a tradição dos precursores e dos fundadores. Foi, assim, aparecendo um renovado interesse por uma sociologia jurídica que não teria unicamente por objeto o direito penal e que progressivamente se difundiu não só nos países germânicos ou anglo-saxões mas também nos de tradição latina, a um lado e outro do Atlântico. Hoje a sociologia jurídica está viva, como resulta da "Apresentação" e testemunha o presente dossiê.

Palavras chave: Sociologia. Sociologia jurídica. Fontes da sociologia jurídica. Questionamentos atuais da sociologia jurídica. 


\section{Society, law, justice: conflictive relations, harmonious relations?}

\section{Raúl Enrique Rojo \& Rodrigo Ghiringhelli de Azevedo}

The origins of legal sociology mingle with those of sociology. That is a result of the interest in Law and legal subjects, both by those seen by Raymond Aron as the pioneers (Montesquieu, Tocqueville and Marx) and the founders of sociology (Durkheim and Weber). However, it is somewhat paradoxical that such interest in legal sociology has had no continuity. Sociologists seem to have lost interest in law in spite of a few isolated initiatives, especially those by Gurvitch, Lévi-Bruhl and Timasheff. In fact, it was as criminology that legal sociology remained being practiced, especially in the United States, even though criminal law remained as its only object of study. That phenomenon is not a result of chance; it is rather a result of the nearly hegemonic academic position enjoyed after the 1960s by a sociology based on suspicion and on a hunt for the actor, which dismissed the study of Law, seen as a mere superstructural product of relations of production, and saw institutions as mirrors that deformed and were deformed by the social relations system. In fact, it was only in mid-1980s that sociologists started to come to terms with the tradition of pioneers and founders. Then a renewed interest in a legal sociology with only criminal law as its objects emerged, and gradually spread not only in Germanic or Anglo-Saxon countries but also in those of Latin tradition, in both sides of the Atlantic. Nowadays, legal sociology is alive, as seen in the "Presentation" and evidenced by the present Dossier.

Key words: Sociology. Legal sociology. Sources of legal sociology. Current issues in legal sociology. 